\title{
Pollution and Purity in Moral and Political Judgment
}

\author{
Yoel Inbar and David Pizarro*
}

Disgust, an emotion that most likely evolved to keep us away from noxious substances and disease, seems especially active in our moral lives. People report feeling disgust in response to many immoral acts (e.g., Rozin et al. 1999), make more severe moral judgments when feeling disgusted (e.g., Wheatley and Haidt 2005), and are more likely to view certain acts as immoral if they have a tendency to be easily disgusted (Horberg et al. 2009). Yet, despite the wealth of evidence linking disgust and morality, the reason for the link remains unclear. This may be because the bulk of empirical work on the topic has been aimed at simply demonstrating that disgust and moral judgment are connected-a claim that, given the influence of rationalist models of moral judgment such as Kohlberg's (1969), is novel and surprising. Fewer researchers have attempted to explain why disgust and moral judgment should be so connected (for recent exceptions, see Kelly 2011 and Tybur et al. 2012). Here, we present an attempt to do so.

Our primary claim is that disgust functions as part of a general motivational system that evolved to keep individuals safe from disease. As such, disgust motivates negative evaluations of acts that are associated with a threat of contamination (e.g., norm violations pertaining to food and sex); negative attitudes toward unfamiliar groups who might pose the threat of contamination through physical contact (e.g., outgroups characterized by these norm violations, or who are unfamiliar); and greater endorsement of certain social and political attitudes that minimize contamination risk (such as increased sexual conservatism, reduced contact between different social 
groups, and hostility toward foreigners). This account provides a theoretical rationale for the observed relationship between disgust and moral judgment, and it is able to unify findings from two literatures that, until now, have been largely separate: research examining the role of disgust in moral judgment, and research examining the effects of pathogen threat on political and social attitudes. One of the conclusions to emerge from this review is that that the link between disgust and morality may be different from what has been assumed by many researchers. Rather than a response to moral violations per se, disgust may instead be linked more generally to judgments about acts, individuals, and groups that pose a pathogen threat.

\section{Disgust and moral judgment: Three claims}

In order to defend this conclusion, it is necessary to first review the evidence linking disgust to moral judgment, and to distinguish between the various ways disgust has been hypothesized to play a role in moral judgment. We have argued previously (Pizarro et al. 2011) that researchers have made three distinct claims regarding the relationship between disgust and moral judgment: (1) that the emotion of disgust is a consequence of perceiving moral violations; (2) that disgust serves to amplify judgments of immorality; and (3) that disgust acts as a moralizer, pushing previously non-moral issues into the moral domain. These claims are not mutually exclusive-all three could be true. However, there are varying degrees of empirical evidence to support each.

According to the "disgust as consequence" view, disgust is the emotional output of a certain kind of moral appraisal. For instance, researchers have found that disgust is elicited by violations of moral "purity" (Rozin et al. 1999), "taboo" moral violations (Gutierrez and Ginner-Sorolla 2007), or being treated unfairly (Chapman et al. 2009). On this view, disgust might drive reactions to immorality - for example, by motivating people to reject or distance themselves from those seen as immoral-but does not play a causal role in determining whether an action is seen as immoral.

In contrast, the "disgust as amplifier" view characterizes disgust as a causal influence on moral judgment, arguing that the presence of disgust during a moral evaluation makes wrong things seem even more wrong. This is a stronger 
claim regarding the role of disgust, and has been made by researchers who have experimentally manipulated disgust independently of the act being evaluated, for example by inducing disgust with a post-hypnotic suggestion (Wheatley and Haidt 2005), with a foul odor, or with disgusting film clips (Schnall et al. 2008).

Finally, the strongest causal claim regarding the influence of disgust on moral judgment is that of "disgust as moralizer." On this view, morally neutral acts can enter the moral sphere by dint of their being perceived as disgusting. For instance, an act (such as smoking) can move from "unhealthy" to "immoral" if reliably accompanied by the emotion of disgust. This claim has the least empirical support of the three, although it is consistent with the finding that "morally dumbfounded" participants defend their self-admittedly irrational moral judgments with an appeal to the disgusting nature of an act (Haidt and Hersch 2001).

Our argument here relies primarily on evidence for the disgust-asconsequence and disgust-as-amplifier views, for which the evidence is strongest (see Pizarro et al. 2011). In particular, the view we will defend here is a combination of these two approaches that takes into account additional research on the specificity of these effects-that disgust is more likely to arise and amplify judgments within a particular domain (namely, when the threat of pathogens is involved).

\section{Why disgust?}

Why should disgust be involved in moral judgment at all, whether as a consequence, amplifier, or moralizer? Theoretical justifications have come largely in the form of broad statements that disgust is an emotional impulse to reject certain objects, individuals, or ideas that, for a variety of reasons, happen to overlap with objects, individuals, and ideas that are morally objectionable. For example, Schnall et al. (2008, p. 1097) write that disgust is "an emotion of social rejection" that is misattributed to many targets of judgment. Cannon et al. (2011, p. 326) write that "disgust is a reaction to offensive objects as well as offensive actions," and Koleva et al. (2012) describe disgust as a response to "social contaminants." Wheatley and Haidt (2005, p. 780) write that disgust is "a kind of information" that influences moral judgments. 
Many of these theoretical explanations are simply restatements of the link between disgust and morality, and do not offer much by way of explanation for it. Rozin et al. (2008, p. 764) offer a more detailed argument, stating that disgust at immoral behavior results from "an opportunistic accretion of new domains of elicitors to a rejection system already in place"-in other words, that moral disgust piggybacks on an older, more basic food rejection response. Along the same lines, Kelly (2011) argues that disgust first evolved to motivate food rejection and pathogen avoidance, and was later "co-opted" to motivate moral judgment and intergroup attitudes. Finally, Tybur et al. (2012) propose an entirely different account, arguing that disgust in response to immorality is an evolved solution to a social coordination problemnamely, the need to coordinate condemnation of specific actions with others. On this account, expressions of disgust function as condemnation signals to others in the vicinity.

All these accounts point to the possibility that moral judgments may be built on more simple psychological systems of avoidance and rejection. But why should the emotion of disgust in particular be involved in reactions to immorality? Kelly (2011) argues that disgust has two features that make it particularly suited to this role: (1) it entails a strong rejection response; and (2) its antecedents (i.e., elicitors) are, at least in part, learned (and therefore flexible). However, humans (and other animals) also show non-disgust-based aversive responses to unpleasant stimuli such as extreme heat or cold, loud or high-pitched sounds, dangerous predators, and so on. In fact, such responses are phylogenetically older than disgust - which is found in its full form only in humans-and are quite flexible, in that people (and other animals) can readily acquire aversions to novel stimuli (Staats and Staats 1958; Tully and Quinn 1985). In contrast, the elicitors of "core" disgust are in fact fairly circumscribed when compared to these other emotional responses, and tend to be limited to food, certain animals, and human body products (Rozin et al. 2008). If moral judgments needed to be built on top of an existing affective response, a more basic rejection system would thus be an equally if not more plausible candidate. Similarly, any number of emotions (such as anger) could be used to signal moral condemnation. Why would natural selection have favored disgust-an emotion that likely had its origins in a gustatory response to potential oral contamination-to serve this purpose? 
It turns out that there is a good reason that disgust, rather than a more general-purpose rejection response, would have become associated with some moral violations - namely, that disgust evolved to motivate individuals not only to avoid ingesting (or touching) poisons and contaminants, but also to distance themselves from people who posed a risk of pathogen transmission. Schaller and colleagues (Faulkner et al. 2004; Park et al. 2003; Schaller and Duncan 2007) have argued that, over the course of human evolution, people developed a "behavioral immune system" that functioned as a first line of defense against exposure to pathogens or parasites. According to this theory, individuals who show cues of infection or disease should trigger the behavioral immune system, leading to disgust and, consequently, rejection or avoidance of that individual. Because this system would have evolved independently of any explicit knowledge about pathogens, its disease detection mechanism would need to be heuristic in naturemost likely, something like "any significant anomaly in an individual's physical appearance." This means that the behavioral immune system can be expected to respond to any individuals who deviate from normative physical appearance, regardless of whether they actually pose a contagion risk (Schaller and Park 2011). Likewise, individuals seen as engaging in unusual (i.e., non-normative) practices regarding food, cleanliness, and sex-activities that carry an especially high risk of pathogen transmissionshould also be likely to evoke disgust and rejection.

Finally, strangers (i.e., members of other groups or tribes) would have been especially likely to harbor novel (and therefore particularly dangerous) infectious agents. Encountering such individuals should thus also activate the behavioral immune system, motivating hostility, rejection, and the accompanying emotion of disgust. Indeed, individuals in hunter-gatherer cultures are often intensely hostile to strangers. The anthropologist Margaret Mead wrote that "most primitive tribes feel that if you run across one of these subhumans from a rival group in the forest, the most appropriate thing to do is bludgeon him to death" (as cited in Bloom 1997, p. 74). Likewise, the geographer and anthropologist Jared Diamond wrote that for New Guinean tribesmen, “to venture out of one's territory to meet [other] humans, even if they lived only a few miles away, was equivalent to suicide" (Diamond 2006, p. 229). 
Importantly, this argument does not assume that all or even most of the individuals or groups evoking disgust and rejection actually pose a risk of infection. But because risks of failing to detect a contagious individual (serious illness and possibly premature death) greatly outweighed the cost of wrongly identifying a harmless individual as contagious (the foregone benefits of a positive interaction), one would expect the behavioral immune system to tend toward hypervigilance (Schaller and Duncan 2007; Shaller and Park 2011). Cues that might be associated with the risk of contamination would have become heuristics, whose mere presence would trigger disgust and rejection, but which could easily be overgeneralized.

\section{The behavioral immune system and social attitudes}

\section{Disease risk and attitudes toward the obese and disabled}

One prediction that follows from the behavioral immune system account is that heightened perceptions of disease risk-either chronic (i.e., dispositional) or situational-should be associated with more negative attitudes toward individuals (heuristically) associated with pathogen threat. This appears to be the case-people who are especially worried about contagious disease (as measured by a subscale of the Perceived Vulnerability to Disease scale; Faulkner et al. 2004; Park et al. 2003) are also more likely to show negative attitudes toward obese people (Park et al. 2007), and people who read bogus news articles about contagious diseases showed more negative associations with physically disabled people (as measured by the Implicit Association Test; Greenwald et al. 1998) than did those who read news articles about other health topics (Park et al. 2003). Of course, neither the obese nor the disabled are likely to actually pose a disease risk, but a perceptual system that responds to significant anomalies in appearance would likely be triggered by these individuals.

\section{Disgust and attitudes toward homosexuals}

A number of researchers have found that disgust tends to be related to harsher attitudes toward gay people. Dasgupta et al. (2009) and Inbar et al. (2012) found 
that induced disgust led to more negative implicit and explicit evaluations of gay men, respectively. Inbar et al. (2009) found that dispositional sensitivity to disgust was associated with more negative implicit evaluations of gay people, and Terrizzi et al. (2010) found a relationship between disgust sensitivity and explicit evaluations of gay people.

\section{Disease risk and attitudes toward foreigners}

Concern about contagious diseases is also associated with negativity toward foreign outgroups, especially unfamiliar ones. For instance, in one study participants who were shown a slideshow highlighting disease and pathogen threats were more inclined (compared to a control group who were shown a slideshow about non-disease threats) to prefer familiar (e.g., Polish) over unfamiliar (e.g., Mongolian) immigrant groups (Faulkner et al. 2004). This claim also finds support from the finding that women in their first trimester of pregnancy (during which immune function is suppressed) are more ethnocentric and xenophobic than women in their second and third trimesters (Navarette et al. 2007).

\section{Other sociopolitical attitudes}

There is also evidence that differences in the strength of the behavioral immune system are related to sociopolitical attitudes more broadly. Individuals who feel more vulnerable to disease consistently provide more conservative responses on a variety of measures tapping social conservatism (Terrizzi et al. 2013), such as right-wing authoritarianism (Altemeyer 1988), social dominance orientation (Pratto et al. 1994), and vertical collectivism (Singelis et al. 1995). Likewise, at the level of group differences, geographic variation in parasite and pathogen prevalence has been found to be associated with variation in the strength of conservative social attitudes in particular cultures. Across 71 world regions, greater historic disease prevalence is associated with more restricted (i.e. conservative) sexual attitudes and lower openness to experience (Schaller and Murray 2008); and across countries and US states, current disease prevalence is associated with greater religiosity and stronger family ties (Fincher and Thornhill 2012). Like the intergroup attitudes described above, these attitudes, 
personality differences, and social preferences all entail greater separation between groups, less experimentation with novel cultural and sexual practices, and less contact with strangers. Although such attitudes clearly have costs (e.g., reduced opportunities for trade and slower adoption of potentially useful cultural innovations), they also have benefits, especially in environments where pathogen threat is high. Less contact with outgroups, lower mobility, and conservation of existing social practices (especially food- and sex-related) minimizes exposure to novel, potentially dangerous pathogens.

\section{The behavioral immune system and moral judgment}

Disgust is the emotion most closely linked to the behavioral immune system, in that it motivates individuals to distance themselves from people or groups seen (implicitly or explicitly) as contaminated or contagious (Oaten et al. 2009). Is it possible that disgust is implicated in moral judgment for similar reasons - that is, because it arises as a reaction to perceived physical contagion threats? The most common disgust-eliciting contagion threats involve sex, food, and outgroups (Oaten et al. 2009). If disgust is involved in moral judgment primarily for violations having to do with contagion threats, moral disgust should largely be limited to these specific domains.

This prediction comes close to the view endorsed by Haidt and Graham (2007) in their description of the moral domain of purity/sanctity. They write that moral disgust is "attached at a minimum to those whose appearance (deformity, obesity, or diseased state), or occupation (the lowest castes in castebased societies are usually involved in disposing of excrement or corpses) makes people feel queasy" (p. 106). Certainly, on the basis of the behavioral immune system literature one would expect avoidance of these groups. However, Haidt and Graham expand their argument, proposing that the moral domain of purity/sanctity includes a metaphorical conception of impurity as well, such that disgust (and judgments of immorality) is also evoked by "those who seem ruled by carnal passions" such as "lust, gluttony, greed, and anger" (p. 106). But how much empirical evidence is there for this more extended, metaphorical role for disgust in moral judgment? In the next section, we examine the research bearing on this question. 


\section{Which moral violations elicit disgust?}

A number of studies have examined people's reactions to moral violations, often by asking them to read about immoral or morally neutral actions and asking them to report their emotional and cognitive evaluations. Results have reliably shown a link between certain types of violations and disgust reactions.

\section{Sex}

Many of the studies showing disgust at moral violations have asked participants to evaluate sexual practices, including homosexuality, incest, and unusual forms of masturbation. Haidt and Hersch (2001), for example, asked liberal and conservative undergraduates to evaluate examples of gay and lesbian sex, unusual masturbation (e.g., a woman who masturbates while holding her favorite teddy bear), and consensual sibling incest. Haidt et al. (1993) did not directly measure disgust responses, but two of the three behaviors that they expected $a$ priori to elicit disgust involved sex (having sex with a dead chicken and then consuming it, and consensual sibling incest). Perhaps the most commonly studied moral violation of this class has been incest-an act known to elicit disgust reliably. For instance, Rozin et al. (1994) asked participants about their responses to incest in general, Royzman et al. (2008) asked participants to evaluate parentchild incest, Gutierrez and Giner-Sorolla (2007) asked about sibling incest, and Horberg et al. (2009) used the same sibling incest vignette originally used by Haidt et al., along with the chicken sex vignette from the same source.

\section{Repugnant foods}

Consumption of repugnant foods has been another commonly studied type of moral violation that appears to reliably elicit disgust. For instance, both Haidt et al. (1993) and Russell and Giner-Sorolla (2011) used a scenario in which a family ate their deceased dog. Similarly, Gutierrez and Giner-Sorolla (2007), and Russell and Giner-Sorolla (2011) presented participants with a scenario in which a scientist grew and consumed a steak made of human muscle cells.

\section{Other moral violations}

Researchers have also uncovered a few moral violations that do not involve sex or food, but that nonetheless appear to elicit disgust (for a recent review, see 
Chapman and Anderson 2013). In one notable example, Chapman et al. (2009) examined reactions to people who made unfair offers in an "ultimatum game." This economic game involves two parties: a "proposer" and a "responder." The proposer suggests a division of a sum (in the current study, \$10) between the two, and the responder can either accept this suggestion or reject it (in which case neither party receives anything). In this study, the proposer was (unbeknownst to the participants) a computer program that sometimes made very unfair offers (i.e., $\$ 9$ for the proposer and $\$ 1$ for the responder). Both participants' self-reports and their facial expressions showed that they felt disgusted by very unfair offers-and the more disgusted they were, the more likely they were to reject the offer. Similarly, when people read about unfairness (e.g., someone cheating at cards), they showed increased activation in a facial muscle (the levator) involved in the expression of disgust (Cannon et al. 2011).

Other studies sometimes cited as showing that disgust can occur as a response to general moral violations are harder to interpret. Some neuroimaging studies have demonstrated overlapping regions of neural activation (as measured by fMRI) for physically disgusting acts and acts of moral "indignation" (Moll et al. 2005). However, the stimuli used in the study to evoke moral indignation often contained basic, physical elicitors of disgust (e.g., "You took your mother out to dinner. At the restaurant, she saw a dead cockroach floating on the soap pan."). The overlapping brain regions found when participants read the "indignation" statements and the "pure disgust" statements (e.g., "One night you were walking on a street. You saw a cat eating its own excrement") could therefore be due to the fact that both statement types contain powerful elicitors of basic disgust.

One study has found that people report feeling disgust in response to pictures that depict violations such as ethnic cleansing or child abuse (but do not show physical disgust elicitors; Simpson, Carter et al. 2006). However, self-reported disgust in this study was highly correlated with self-reported anger, leaving open the possibility that participants were using the term in a metaphorical rather than literal sense (see Nabi 2002). Similarly, young children agree that moral violations such as "being very mean to someone" can be described as "disgusting," and that a disgust face "can go with" these violations (Danovitch and Bloom 2009). However, in these studies other 
negative emotion words and faces were not possible responses, leaving open the possibility that children simply endorsed the one negatively valenced emotion available to them.

\section{Summary}

Most disgusting moral violations involve unusual sex or foodstuffs (or, in the case of the "chicken sex" vignette, both). This is what one would expect if disgust-evoking moral violations activated the behavioral immune system and negative evaluations of these acts were driven by avoidance in the same way that behavioral immune system-relevant intergroup and political attitudes are. The pattern of data is also compatible with the first part of the view advanced by Haidt and Graham (2007) — that disgust functions as the guardian of physical purity. However, empirical support for the second half of their view-that violations of spiritual purity also evoke disgust-is lacking.

Furthermore, some findings are explained poorly by both accountsnamely, that unfair or selfish behavior also evokes disgust, at least under some circumstances. Such behavior is neither straightforwardly related to pathogen threats, nor to physical or spiritual purity. Of course, these findings are from only two studies, and further research is necessary to determine the robustness and generality of the relationship between witnessing unfairness or selfishness and disgust. One (admittedly speculative) possibility is that cheaters and nonreciprocators are seen as an outgroup that evokes a distancing motivation in the same way that groups seen as unfamiliar or unclean do.

\section{Induced disgust and harsher moral judgment}

A number of studies have experimentally induced disgust (for example, using bad smells, dirty surroundings, or disgusting film clips), and examined the effects of this extraneously induced disgust on people's moral judgments. In the terminology used by Pizarro, Inbar, and Helion (2011), these studies have been used to test the "disgust as amplifier" and/or "disgust as moralizer" hypotheses. Generally, these studies have found that incidental disgust makes moral judgments harsher for a wide range of infractions, including incest, eating one's dog, bribery, stealing library books, falsifying one's resume, and 
masturbating with a kitten (Schnall et al. 2008; Wheatley and Haidt 2005). Schnall et al. examined whether the type of moral infraction ("purity-violating," e.g. dog-eating or sex between first cousins vs. "non-purity-violating," e.g. falsifying one's resume) moderated the effects of induced disgust on moral judgment and found that it did not. However, Horberg et al. (2009) found that inducing disgust (as opposed to sadness) had a stronger amplification effect on judgments of "purity violations" (such as sexual promiscuity) than "harm/care violations" (such as kicking a dog). Thus, there is conflicting evidence on whether inducing disgust selectively affects certain kinds of moral judgments.

However, studies that demonstrate the effects of experimental inductions of disgust on moral evaluation do not serve as evidence that disgust is naturally elicited by moral violations. An analogy to research on the effects of emotion on judgment is useful here. Research has shown that extraneously manipulating emotions such as fear, sadness, anger, or even disgust can affect a wide range of judgments and decisions (Loewenstein and Lerner 2003). But that does not mean that these emotions naturally arise when making these judgments. No one would conclude that because disgust makes one more willing to sell an item that one has been given (Lerner et al. 2004), disgust therefore also arises naturally when one is deciding whether to sell or keep an item. Similarly, showing that disgust affects judgments of certain moral violations is not informative about whether disgust is a naturally occurring response to witnessing such violations.

\section{The effects of cleanliness on moral and political judgment}

If moral and political judgments are motivated at least partly by the threat of contamination, drawing attention to this threat by asking participants to wash their hands (or perhaps even by simply exposing them to washingrelated stimuli) should have similar effects on judgment as other pathogen primes. There is some evidence for this: Helzer and Pizarro (2011) found that participants who were standing next to a hand-sanitizer dispenser described themselves as more politically conservative, and that those who had just used an 
antiseptic hand wipe were more negative in their moral judgments of unusual sexual behaviors (e.g., consensual incest between half-siblings), but not in their judgments of putatively immoral acts that did not involve sexuality. Similarly, Zhong et al. (2010) demonstrated that hand-washing made participants more conservative (i.e., more negative) on a number of social issues related mainly to sexual morality (e.g., casual sex, pornography, and adultery).

However, researchers who have adopted a more metaphorical notion of purity have made exactly the opposite prediction regarding the effects of cleanliness on moral judgment, arguing that if feeling clean is psychologically the opposite of feeling disgusted, making cleanliness salient should reduce feelings of disgust and therefore make moral judgments less harsh. There is also some evidence for this view: Priming participants with purity-related words (e.g. "pure," "immaculate," and "pristine") made them marginally less harsh when judging moral violations (Schnall et al. 2008, Study 1), and asking participants to wash their hands after watching a disgusting film clip attenuated the effects of the clip on moral judgments (Schnall et al., Study 2).

How to reconcile these conflicting results? First, it is likely that in Schnall et al.s (2008) Study 2, in which all participants watched a film clip showing a man crawling into a filthy toilet, physical contamination threats were salient for all participants. When contamination is salient, hand-washing may have a palliative effect, whereas when contamination is not already salient, handwashing may instead prime pathogen concerns. However, this still leaves the results of Schnall et al.s Study 1 unexplained. It is possible that purity-related words do not prime physical pathogen threats. Such simple cognitive primes may simply not be enough to engage a motivational system built to avoid pathogens, but may be effective in reminding individuals of other cleanlinessrelated concepts. It is also possible that this single, marginally significant result from a low-powered (total $\mathrm{N}=40$ ) study is anomalous. This is a question that can only be settled by future research.

Putting this (possibly anomalous) result aside, the account we propose here offers a parsimonious explanation why disgust and its opposite-cleanlinesswould show parallel effects on people's moral judgments and sociopolitical attitudes. Because both disgust and hand-washing make the threat of physical contamination salient, their effects on certain kinds of moral and sociopolitical judgments should be similar. In contrast, a more metaphorical view of the role 
of disgust in moral judgment would - as outlined above-predict that physical cleansing should make moral judgments less harsh (and, possibly, make attitudes toward sexual morality-related social issues more tolerant). This, of course, is not what the bulk of the evidence shows, although more research is needed to reconcile the conflicting findings in this area.

\section{Disgusting but permissible actions}

One potential objection to the account we defend here is that there are many behaviors that are judged by most as disgusting yet morally permissible, such as picking one's nose in private (see also Royzman et al. 2009). However, our argument does not require that all disgusting acts be seen as immoral (or, for that matter, that all immoral acts be seen as disgusting). Rather, we argue that reactions to certain moral violations (primarily those involving sex or food), certain sociomoral attitudes (primarily toward individuals seen as physically abnormal, norm-violating, or foreign), and certain political attitudes (primarily those related to sexual conservatism, reduced contact between different social groups, and hostility toward outsiders) rely on a shared motivational system; that this system evolved due to the adaptive benefits of responding to disease or contamination threats with rejection and avoidance; and that its primary motivating emotion is disgust.

This account allows, but does not require, that disgust might extend to other kinds of moral violations as well (as we have described above, evidence for such extension is scarce). One way that such an extension could happen is that disgust may become "attached" to some behaviors for which there already exist non-moral proscriptive norms (e.g., smoking or eating meat; Nichols 2004). In these cases, the pairing of disgust with (or the tendency to be disgusted by) the behavior might cause it to be "pushed" into the moral domain-especially if the behavior can be construed as harmful. Such a moralization process might be observed with longitudinal data comparing moral attitudes toward disgusting and non-disgusting behaviors that either have an existing (but nonmoral) proscriptive norm and those which do not. If our account is correct, one would expect moralization over time to occur only in the disgusting behaviors for which there are already conventional norms in place. 


\section{Conclusion}

Reviewing the evidence linking moral violations and disgust shows that with a few exceptions, the moral violations that elicit disgust involve food, sex, or both. This is consistent with the view that seeing such acts as immoral and feeling disgust in response to them result from activation of the behavioral immune system, an evolved motivational system that responds to physical contamination threats. We believe that this account parsimoniously explains disgust's connection with moral judgments, sociomoral attitudes, and political beliefs. It also suggests that the link between disgust and morality may be different from what has been assumed by many researchers.

Although there is an empirical connection between disgust and seeing a variety of acts as immoral, this may be due to the specific content of the acts in question rather than to a more general relationship between disgust and judgments of immorality. A great deal of research points to a reliable connection between disgust and acts, individuals, or groups that are threatening because of the potential for physical contamination, whereas there is as yet little evidence that disgust is a reaction to immoral behaviors per se.

\section{Note}

* Author's Note: Yoel Inbar, Tilburg University, and David Pizarro, Cornell University. Corresponding Author: Yoel Inbar, Department of Social Psychology, Tilburg University, Email: yinbar@uvt.nl.

\section{References}

Altemeyer, R. A. (1998). The other “authoritarian personality." In M. P. Zanna (ed.), Advances in Experimental Social Psychology (Vol. 30). New York: Academic Press, pp. 47-91.

Bloom, H. (1997). The Lucifer Principle: A Scientific Expedition into the Forces of History. New York: Atlantic Monthly Press.

Cannon, P. R., Schnall, S., and White, M. (2011). Transgressions and expressions: Affective facial muscle activity predicts moral judgments. Social Psychological and Personality Science, 2, 325-31. 
Chapman, H. A., and Anderson, A. K. (2013). Things rank and gross in nature: A review and synthesis of moral disgust. Psychological Bulletin, 139, 300-27.

Chapman, H. A., Kim, D. A., Susskind, J. M., and Anderson, A. K. (2009). In bad taste: Evidence for the oral origins of moral disgust. Science, 323, 1222-6.

Danovitch, J., and Bloom, P. (2009). Children's extension of disgust to physical and moral events. Emotion, 9, 107-12.

Dasgupta, N., DeSteno, D. A., Williams, L., and Hunsinger, M. (2009). Fanning the flames of prejudice: The influence of specific incidental emotions on implicit prejudice. Emotion, 9, 585-91.

Diamond, J. M. (2006). The Third Chimpanzee: The Evolution and Future of the Human Animal. New York: Harper Perennial.

Faulkner, J., Schaller, M., Park, J. H., and Duncan, L. A. (2004). Evolved diseaseavoidance mechanisms and contemporary xenophobic attitudes. Group Processes and Intergroup Behavior, 7, 333-53.

Fincher, C. L., and Thornhill, R. (2012). Parasite-stress promotes in-group assortative sociality: The cases of strong family ties and heightened religiosity. Behavioral and Brain Sciences, 35, 61-79.

Graham, J., Haidt, J., and Nosek, B. (2009). Liberals and conservatives use different sets of moral foundations. Journal of Personality and Social Psychology, 96, 1029-46.

Greenwald, A. G., McGhee, D. E., and Schwartz, J. L. K. (1998). Measuring individual differences in implicit cognition: The implicit association test. Journal of Personality and Social Psychology, 74, 1464-80.

Gutierrez, R., and Giner-Sorolla, R. S. (2007). Anger, disgust, and presumption of harm as reactions to taboo-breaking behaviors. Emotion, 7, 853-68.

Haidt, J. (2001). The emotional dog and its rational tail: A social intuitionist approach to moral judgment. Psychological Review, 108, 814-34.

Haidt, J., and Graham, J. (2007). When morality opposes justice: Conservatives have moral intuitions that liberals may not recognize. Social Justice Research, 20, 98-116.

Haidt, J., and Hersh, M. (2001). Sexual morality: The cultures and emotions of conservatives and liberals. Journal of Applied Social Psychology, 31, 191-221.

Helzer, E. G., and Pizarro, D. A. (2011). Dirty liberals! Reminders of physical cleanliness influence moral and political attitudes. Psychological Science, 22, 517-22.

Horberg, E. J., Oveis, C., Keltner, D., and Cohen, A. B. (2009). Disgust and the moralization of purity. Journal of Personality and Social Psychology, 97, 963-76.

Inbar, Y., Pizarro, D., Knobe, J., and Bloom, P. (2009). Disgust sensitivity predicts intuitive disapproval of gays. Emotion, 9, 435-9.

Inbar, Y., Pizarro, D. A., and Bloom, P. (2009). Conservatives are more easily disgusted. Cognition \& Emotion, 23, 714-25. 
Kelly, D. (2011). Yuck! The Nature and Moral Significance of Disgust. Cambridge, MA: The MIT Press.

Kohlberg, L. (1969). Stage and sequence: The cognitive-developmental approach to socialization. In D. A. Goslin (ed.), Handbook of Socialization Theory and Research. Chicago, IL: Rand McNally, pp. 347-480.

Koleva, S. P., Graham, J., Iyer, R., Ditto, P. H., and Haidt, J. (2012). Tracing the threads: How five moral concerns (especially Purity) help explain culture war attitudes. Journal of Research in Personality, 46, 184-94.

Lerner, J. S., Small, D. A., and Loewenstein, G. (2004). Heart strings and purse strings carryover effects of emotions on economic decisions. Psychological Science, 15, $337-41$.

Loewenstein, G., and Lerner, J. S. (2003). The role of affect in decision making. In R. J. Davidson, K. R. Scherer, and H. H. Goldsmith (eds), Handbook of Affective Science. New York: Oxford University Press, pp. 619-42.

Moll, J., de Oliveira-Souza, R., Moll, F. T., Ignácio, F. A., Bramati, I. E., CaparelliDáquer, E. M., and Eslinger, P. J. (2005). The moral affiliations of disgust: A functional MRI study. Cognitive and Behavioral Neurology, 18, 68-78.

Nabi, R. L. (2002). The theoretical versus the lay meaning of disgust: Implications for emotion research. Cognition and Emotion, 16, 695-703.

Navarrete, C. D., Fessler, D. M. T., and Eng, S. J. (2007). Elevated ethnocentrism in the first trimester of pregnancy. Evolution and Human Behavior, 28, 60-5.

Nichols, S. (2004). Sentimental Rules: On the Natural Foundations of Moral Judgment. New York: Oxford University Press.

Oaten, M., Stevenson, R. J., and Case, T. I. (2009). Disgust as a disease-avoidance mechanism. Psychological Bulletin, 135, 303-21.

Park, J. H., Faulkner, J., and Schaller, M. (2003). Evolved disease-avoidance processes and contemporary anti-social behavior: Prejudicial attitudes and avoidance of people with physical disabilities. Journal of Nonverbal Behavior, 27, 65-87.

Park, J. H., Schaller, M., and Crandall, C. S. (2007). Pathogen-avoidance mechanisms and the stigmatization of obese people. Evolution and Human Behavior, 28, 410-14.

Pizarro, D. A., Inbar, Y., and Helion, C. (2011). On disgust and moral judgment. Emotion Review, 3, 267-8.

Pratto, F., Sidanius, J., Stallworth, L. M., and Malle, B. F. (1994). Social dominance orientation: A personality variable predicting social and political attitudes. Journal of Personality and Social Psychology, 67, 741-63.

Royzman, E. B., Leeman, R. F., and Baron, J. (2009). Unsentimental ethics: Towards a content-specific account of the moral-conventional distinction. Cognition, 112, $159-74$. 
Royzman, E. B., Leeman, R. F., and Sabini, J. (2008). “You make me sick”: Moral dyspepsia as a reaction to third-party sibling incest. Motivation and Emotion, 32, $100-8$.

Rozin, P., Haidt, J., and McCauley, C. R. (2008). Disgust. In M. Lewis, J. M. HavilandJones, and L. F. Barrett (eds), Handbook of Emotions (3rd ed.). New York: Guilford, pp. 757-76.

Rozin, P., Lowery, L., Imada, S., and Haidt, J. (1999). The moral-emotion triad hypothesis: A mapping between three moral emotions (contempt, anger, disgust) and three moral ethics (community, autonomy, divinity). Journal of Personality and Social Psychology, 76, 574-86.

Russell, P. S., and Giner-Sorolla, R. (2011). Moral anger, but not moral disgust, responds to intentionality. Emotion, 11, 233-40.

Schaller, M., and Duncan, L. A. (2007). The behavioral immune system: Its evolution and social psychological implications. In J. P. Forgas, M. G. Haselton, and W. von Hippel (eds), Evolution and the Social Mind: Evolutionary Psychology and Social Cognition. New York: Psychology Press, pp. 293-307.

Schaller, M., and Murray, D. R. (2008). Pathogens, personality, and culture: Disease prevalence predicts worldwide variability in sociosexuality, extraversion, and openness to experience. Journal of Personality and Social Psychology, 95, 212-21.

Schaller, M., and Park, J. H. (2011). The behavioral immune system (and why it matters). Current Directions in Psychological Science, 20, 99-103.

Schnall, S., Benton, J., and Harvey, S. (2008). With a clean conscience: Cleanliness reduces the severity of moral judgments. Psychological Science, 19, 1219-22.

Schnall, S., Haidt, J., Clore, G. L., and Jordan, A. H. (2008). Disgust as embodied moral judgment. Personality and Social Psychology Bulletin, 34, 1096-109.

Simpson, J., Carter, S., Anthony, S. H., and Overton, P. G. (2006). Is disgust a homogeneous emotion? Motivation and Emotion, 30, 31-41.

Singelis, T. M., Triandis, H. C., Bhawuk, D. P. S., and Gelfand, M. J. (1995). Horizontal and vertical dimensions of individualism and collectivism: A theoretical and measurement refinement. Cross-Cultural Research, 29, 240-75.

Staats, A. W., and Staats, C. K. (1958). Attitudes established by classical conditioning. The Journal of Abnormal and Social Psychology, 57, 37-40.

Terrizzi, J. A., Shook, N. J., and McDaniel, M. A. (2013). The behavioral immune system and social conservatism: A meta-analysis. Evolution and Human Behavior, 34, 99-108.

Terrizzi, J. A., Shook, N. J., and Ventis, W. L. (2010). Disgust: A predictor of social conservatism and prejudicial attitudes toward homosexuals. Personality and Individual Differences, 49, 587-592. 
Tully, T., and Quinn, W. G. (1985). Classical conditioning and retention in normal and mutant Drosophila melanogaster. Journal of Comparative Physiology A, 157(2), 263-77.

Tybur, J. M., Lieberman, D., Kurzban, R., and DeScioli, P. (2012). Disgust: Evolved function and structure. Psychological Review, 120, 65-84.

Wheatley, T., and Haidt, J. (2005). Hypnotic disgust makes moral judgments more severe. Psychological Science, 16, 780-4.

Zhong, C. B., Strejcek, B., and Sivanathan, N. (2010). A clean self can render harsh moral judgment. Journal of Experimental Social Psychology, 46, 859-62. 